\title{
Os desafios de um programa federativo - Programa nacional de segurança pública com cidadania
}

\author{
Letícia Figueira Moutinho Kulaitis $^{63}$
}

\section{RESUMO}

A prática de repasse de recursos da União a Estados e Municípios é corrente em um Estado federativo como o Brasil. No entanto, a distribuição dos recursos federais perpassa também pela normatização de seu modo de execução, ou seja, sua aplicação implica cumprimento por Estados e Municípios das diretrizes e da legislação preconizada pela União. $O$ presente artigo pretende analisar os desafios postos ao exercício de um programa federativo, tomando como modelo a análise do Programa Nacional de Segurança Pública com Cidadania PRONASCI, programa do Ministério da Justiça, lançado em 2007.

Palavras-chave: Políticas Públicas; Descentralização e Segurança Pública.

\section{ABSTRACT}

The practice of transfer of federal funds to states and municipalities is current in a Federated State as Brazil. However, the distribution of federal funds also implies the standardization of means of execution, in other words, its application requires compliance by states and municipalities with the guidelines and legislation advocated by the federal government. This article aims to analyze the challenges posed to the exercise of a federal program, taking as example the Programa Nacional de Segurança Pública com Cidadania - PRONASCl, program of the Ministry of Justice, launched in 2007.

Keywords: Public Policy Decentralization and Public Security.

A constituição da república federativa do Brasil (BRASIL, 1988) estabelece a distribuição de competências entre membros que compõem a federação e

63 Graduada em Ciências Sociais pela Universidade Federal do Paraná (2002) e mestre em Sociologia pela Universidade Federal do Paraná (2004). Atualmente cursa o Doutorado em Sociologia do Programa de Pós-Graduação da Universidade Federal do Paraná. 
preconiza a integração entre União, Estados e Municípios para a atuação em determinadas matérias.

A execução de programas federativos têm sido uma das principais vias para a realização dos objetivos preconizados pela Carta Magna. Estes programas são concebidos e estruturados pelo Governo Federal e executados por Estados e Municípios, em parceria com a União que, nesse sentido, descentraliza seus recursos.

A prática de repasse de recursos da União a Estados e Municípios é, portanto, corrente em um Estado federativo como o Brasil. No entanto, a distribuição dos recursos federais perpassa também pela normatização de seu modo de execução, ou seja, sua aplicação implica na conversão de Estados e Municípios ás diretrizes e á legislação preconizada pela União.

Entretanto, é necessário apontar que a execução de programas federativos não é em si um indicativo da existência ou construção de uma política nacional acerca de sua matéria.

Sobre os programas sociais, no âmbito do Sistema de Proteção Social, Arretche afirma:

\footnotetext{
Penso que existe uma larga distância entre, de um lado, a possível emergência de programas sociais em um número - mesmo que expressivo - de localidades com administrações mais diretamente sensíveis aos problemas populares e, de outro, a construção de um novo modelo de prestação de serviços sociais de âmbito nacional com características descentralizadas. (ARRETCHE, 2000, p. 23).
}

Embora a autora refira-se especificamente às políticas de assistência social, sua percepção aplica-se ás demais áreas de atuação do governo, pois quando essa atuação está apoiada no caráter federativo, os pontos de partida dessa política, ainda que nacional, são diversos.

O debate acerca destes pontos de partidas, responsáveis por diferentes configurações locais para os programas federativos, passa, entre outras questões, pela diversidade, entre as unidades da federação, quanto às tradições políticas, estruturas administrativas e capacidade de gasto com determinada política 
pública. Como sinaliza Arretche (2000, p. 24), as unidades subnacionais de governo brasileiras são absolutamente desiguais quanto à sua capacidade de gasto.

A questão da estrutura administrativa também se configura como importante elemento para a análise das políticas públicas de caráter federativo, pois exprime a capacidade de gestão de uma determinada unidade da federação. Nesse sentido, é importante destacar que não há correlação direta entre o fato de que um dado Estado ou Município esteja efetuando despesas em uma dada área de política social e a existência de gestão naquela área (ARRETCHE, 2000, p. 24).

A capacidade de gestão, para além de uma questão orçamentária, trata-se da estrutura administrativa, organizacional e operacional (instalações, equipamentos e tecnologia) e pessoal qualificado de que se dispõe para a realização da política. Destaca-se que a existência de políticas sociais supõe a institucionalização de capacidade técnica (financeira, administrativa e de recursos humanos) para garantir uma relativa continuidade no fluxo de oferta de um dado bem ou serviço. Diferentemente de uma política institucionalizada, programas sociais podem surgir e desaparecer em um curto período de tempo. (ARRETCHE, 2000, p. 24).

Em Estados federativos, respeitadas as disposições constitucionais, os diversos níveis de governo podem implementar programas sociais os mais diversos (ARRETCHE, 2000, p. 23). No entanto, a existência de um programa não significa a emergência de uma política.

Para efeito de análise, o campo da segurança pública é tomado, neste artigo, como central para a discussão de uma proposta de programa federativo e os desafios postos a sua realização.

No Brasil, o órgão responsável pela construção da política nacional de segurança é a Secretaria Nacional de Segurança Pública - SENASP. Cabe à SENASP, instituída pelo Decreto № 2.315, de 4 de setembro de 1997, assessorar o Ministro de Estado da Justiça na definição e implementação da política nacional 
de segurança pública e assim sendo, assegurar que os termos que compreendem a definição desta política sejam difundidos em todo o território nacional.

O Programa Nacional de Segurança Pública com Cidadania - PRONASCI, analisado neste artigo, foi desenvolvido de acordo com essa atribuição, qual seja de orientar o rumo das ações de segurança pública nos Estados e Municípios. No entanto, para se compreender seu desenho, é preciso conhecer os antecedentes deste Programa que toma, no ano de 2007, os jovens entre 15 e 24 anos $^{64}$ como foco central da política nacional de segurança pública.

A partir de 1997 emergiram diversas ações na esfera federal voltadas para a juventude. A associação entre juventude e violência perpassa tais ações que buscam ora o controle ora a compensação de problemas que atingem a juventude. Estas ações encontravam-se no âmbito da Educação, da Assistência Social, do Esporte, da Saúde ainda que de forma descoordenada (SPOSITO e CARRANO, 2003, p. 21).

Em 20 de junho de 2000 foi lançado, pela SENASP, o Plano Nacional de Segurança Pública (PNSP), estruturado em quinze compromissos ordenados, por sua vez, em 124 ações estratégicas. Foram definidos, no Plano, os participantes de cada compromisso e apresentados os resultados esperados entre 2000 e 2002. As ações estratégicas, previstas no PNSP, são atribuídas não só à União, mas também aos Estados e Municípios, por meio da cooperação com o Governo Federal e do estímulo ao desenvolvimento de políticas de segurança por estes entes.

Neste momento de definição e estruturação dos rumos da política nacional, a questão da juventude começou a tomar forma como integrante do campo da segurança pública. Os compromissos que fazem referências à questão

64 A faixa etária atendida pelo Programa foi definida pela Lei 11.530 de 24 de outubro de 2007. Cabe destacar que, na proposta enviada ao Congresso, o Governo Federal pretendia que o Programa atendesse jovens entre 15 e 29 anos. Com isso, o Programa estaria alinhado com a definição de juventude como proposta por organismos internacionais (Organização das Nações Unidas, Organização Mundial de Saúde e Organização das Nações Unidas para a Educação, a Ciência e a Cultura). No entanto, o Senado alterou a proposta de lei, reduzindo o recorte etário ao limite de 24 anos. 
da adolescência e/ou da juventude ${ }^{65}$ são aqueles voltados para a regulação dos meios de comunicação com vistas a impedir a exposição de crianças e adolescentes à violência ${ }^{66} \mathrm{e}$ na inibição da atuação de gangues. A preocupação com a juventude, diante do crescimento da violência urbana é expressa da seguinte maneira:

Nesse contexto, os jovens, especialmente aqueles situados na faixa etária de 14 a 24 anos, se apresentam ao mesmo tempo como as vítimas mais prováveis da violência, mas também como os violentos mais prováveis. A sociedade brasileira não foge a essa tendência moderna. $O$ Brasil está cheio de exemplos recentes que expressam omissão ou superproteção das famílias, da escola e dos poderes públicos, que não conseguem construir, principalmente com a participação dos jovens, uma perspectiva de futuro. (MINISTÉRIO DA JUSTIÇA, 2000, p.20).

São associadas ao compromisso de Inibição de Gangues e Combate à desordem social às seguintes ações estratégicas: redução de consumo de bebida alcóolica, criação de delegacias especializadas no atendimento a adolescentes, incentivo a aplicação de medidas socioeducativas aos adolescentes em conflito com a lei, a fiscalização de organizações, grupos e associações que reúnem jovens para evitar que estes sejam espaços de incentivo a violência, restauração de espaços públicos de convivência, como praças e parques, e projetos educativos voltados aos profissionais de segurança pública e à comunidade (MINISTÉRIO DA JUSTIÇA, 2000, p.20).

Percebe-se que há, no documento do PNSP, uma visão dualizada da juventude. Se por um lado, considera-se que os adolescentes e jovens são estimulados a violência por meio da mídia e das associações em que se reúnem,

65 Para efeitos de análise da política nacional de segurança pública, este artigo refere-se à juventude como aqueles que se encontram entre 15 e 24 anos. Segue-se, portanto, os preceitos da legislação que regula o PRONASCI. Já em relação ao termo adolescência, refere-se à fase compreendida entre 12 e 18 anos como preconizado pelo Estatuto da Criança e do Adolescente, em seu 20 artigo (BRASIL, 1999, p.1).

66 A atividade de classificação indicativa de faixa etária para exibição da programação cultural, especialmente cinema e televisão é desde então competência do Ministério da Justiça. Cabe ao Ministério aplicar multas administrativas às empresas que descumprirem as orientações de classificação apontadas pelo Ministério, bem como destinar os recursos decorrentes dessas multas para o Fundo Nacional da Criança e do Adolescente, a serem utilizados no financiamento de programas de cunho educativo a serem veiculados pela emissora violadora (MINISTÉRIO DA JUSTIÇA, 2000, p. 16). 
por outro, são violentos em si e por $\mathrm{si}^{67}$. A resposta proposta pelo Plano é a adoção de medidas educativas que tem por objetivo inibir o comportamento violento juvenil.

O advento do PNSP consolidou a SENASP como o órgão responsável pela implementação da política nacional de segurança pública, ou seja, dos compromissos estabelecidos pelo Plano. A partir deste momento, Cano (2006, p.139) observa que "a Secretaria Nacional de Segurança Pública (SENASP) do Ministério da Justiça, órgão com uma atuação anteriormente discreta, foi reorganizada e fortalecida para acompanhar e implementar essas novas tarefas".

O PNSP foi responsável pela instituição, por meio da medida provisória no 2.120-8, de 27 de dezembro de 2000 convertida na lei no 10.201, de 14 de fevereiro de 2001, do Fundo Nacional de Segurança Pública - FNSP. O FNSP foi criado com o objetivo de apoiar projetos na área de segurança pública e de prevenção à violência, enquadrados nas diretrizes do plano de segurança pública do Governo Federal.

Desde então, por meio do Fundo Nacional de Segurança Pública, a SENASP orienta, seleciona, aprova e financia projetos de entes federados (Estados e Municípios) na área de segurança pública. Os projetos podem ser divididos em dois grandes grupos: ações de prevenção e ações de repressão. Essa dicotomia está presente não só na lógica de funcionamento do FNSP como também nos relatórios, manuais e cartilhas produzidos pela SENASP. Os projetos de repressão, por conta da norma constitucional ${ }^{68}$, são destinados às forças policiais representadas por suas Secretarias Estaduais de Segurança. Já os

67 Nesse sentido é pertinente observação da Secretaria Nacional de Direitos Humanos de que "diante de uma situação de violência, a criança em geral é percebida como vítima, independentemente de sua conduta. Já o adolescente que comete uma infração é percebido de forma ambígua, em parte autor e em parte vítima dos seus comportamentos. Por fim, o adulto transgressor, mesmo jovem, é considerado plenamente responsável e tende a ser visto como um perigo para a sociedade" (SECRETARIA NACIONAL DE DIREITOS HUMANOS, 2012, p. 20).

680 artigo 144 da Constituição determina quais órgãos seriam responsáveis pela segurança pública, dever do Estado, direito e responsabilidade de todos: Polícia Federal, Polícia Rodoviária Federal, Polícias Civis, Policiais Militares e corpo de bombeiros militares (BRASIL, 2007). 
projetos de prevenção são destinados, por suposta vocação, aos municípios. O sentido desta vocação, passa pelo recorte da especificidade local, segue o princípio de que a experiência do crime, da violência ocorre nas cidades. Estes projetos são definidos pela SENASP (2008) como aqueles que antecedem a ocorrência de fatos delituosos e reduzem a possibilidade de ocorrência de crimes e de situações de violência.

Nesse contexto, a SENASP pode ser vista como um órgão que executa a articulação e a mediação, entre diferentes grupos sociais, para identificação de problemas na área de segurança pública bem como a responsável pelo estabelecimento de um discurso integrado sobre as soluções apresentadas a estes problemas.

Com o objetivo de difundir diretrizes sobre as ações de prevenção, o Departamento de Políticas, Programas e Projetos - DEPRO/SENASP desenvolveu, em 2005, com o apoio do Programa das Nações Unidas para o Desenvolvimento - PNUD/Brasil - um Guia para a prevenção do crime e da violência destinado aos gestores municipais. Embora a SENASP reconheça que os problemas relacionados à segurança pública não são os mesmos em todas as regiões ou em todas as cidades brasileiras, o que nos leva a concluir que arranjos locais poderiam ser considerados no combate do crime, o Guia pretende sistematizar alguns princípios básicos que independem das circunstâncias particulares.

Para que os Municípios possam orientar sua política municipal de segurança de acordo com as diretrizes propostas pela SENASP, o Guia conta com um glossário definindo, entre outros termos, crime, violência, prevenção do crime e da violência, fator de risco, vulnerabilidade e política/programa de prevenção do crime e da violência.

É necessário observar que a SENASP, como responsável pela definição e implementação da política nacional de segurança pública, tem oscilado entre apontar o jovem como principal vítima da violência em nosso país e identificar o jovem como protagonista da violência. Tal instabilidade ocasiona a adoção pelo 
Governo Federal, Governos Estaduais e Municipais de ações de prevenção ou de repressão da violência e da criminalidade dada à percepção construída pela SENASP acerca da juventude. No entanto é possível perceber no âmbito das políticas nacionais de segurança, que mesmo quando o jovem é reduzido à vítima, a atenção que se volta para ele é constituída pela noção de que, por conta das características atribuídas à juventude e de sua situação de marginalidade social, este caminharia numa linha tênue entre a prática concreta da criminalidade e a possibilidade efetiva de realizá-la.

Em 2007, o Banco Mundial produziu um relatório sobre a situação da juventude no Brasil, de acordo com o documento:

A maior parte da juventude brasileira encontra-se bem encaminhada e com boas possibilidades de tornar-se parte produtiva da sociedade, com condições de contribuir para o bem comum e para o interesse coletivo. (...). Entretanto, existe uma minoria de pessoas que não estão atravessando com sucesso os anos experimentais da juventude. Esses e essas jovens, usualmente chamados de jovens em situação de risco, são o tema deste Relatório. (BANCO MUNDIAL, 2007, p. 9).

Sendo assim, como aponta a instituição, a definição usual de jovens em situação de risco assume um papel central no trato da questão da juventude. Aqueles que, por conta de seu comportamento, são considerados um risco para a sociedade. Trata-se de um risco individual e não social. Retira-se, portanto, o peso dos problemas sociais que atingem a juventude ou ainda quando os mesmos são considerados, minimizá-los ou solucioná-los depende de uma atitude individualizada.

O jovem, de acordo com essa corrente de pensamento, deverá ser orientado no caminho da profissionalização como alternativa a conduta criminosa buscando minimizar os custos sociais de seu comportamento de risco ${ }^{69}$. O Banco Mundial orienta o Brasil que:

A prevenção desses comportamentos [de risco assumidos pela juventude] aumentaria o bem-estar das pessoas em termos de melhor

69 Como destaca Santos (1998, p. 24), a perspectiva de cidadania presente nesta corrente é aquela que "está embutida na profissão e os direitos do cidadão restringem-se aos direitos do lugar que ocupa no processo produtivo, tal como reconhecido por lei". 
status de saúde, maiores ganhos potenciais e maiores possibilidades de desfrutar ganhos potenciais e maiores possibilidade de desfrutar a vida. Além disso, também eliminaria custos sociais, liberando recursos públicos para serem gastos em outras iniciativas, aumentando o crescimento à medida, que as pessoas fossem acumulando capital humano e, assim, tendo maior capacidade produtiva. Recursos públicos gastos no desenvolvimento de jovens precisam, necessariamente, ser parte da estratégia de investimento de um país para promover 0 seu desenvolvimento econômico e social. A atual estratégia de investimento para o desenvolvimento humano no Brasil está aquém da estratégia ótima de desenvolvimento. (BANCO MUNDIAL, 2007, p. 21).

É no contexto deste debate sobre a vulnerabilidade social dos jovens e da suposta escalada dos homicídios cometidos por essa faixa etária que é criado o PRONASCI ${ }^{70}$. Consolidando o foco etário e territorial da política nacional de segurança proposta pela SENASP, o Programa foi lançado em agosto de 2007. O programa teve suas ações dirigidas para jovens entre 15 e 24 anos, identificados como aqueles em situação infracional ou no caminho de situação infracional: adolescentes em conflito com a lei, jovens oriundos do serviço militar obrigatório, jovens presos, jovens egressos do sistema penitenciário e jovens em situação de descontrole familiar grave (MINISTÉRIO DA JUSTIÇA, 2008a, p.5). Estes jovens não estariam integrados aos programas sociais do Governo Federal.

A percepção desta juventude é, manifesta pelo Ministério da Justiça, em Cartilha do PRONASCI:

Os índices de mortalidade por causas não naturais e os números de prisões de jovens mostram que a juventude brasileira está sofrendo mais do que qualquer outra faixa etária, as consequências da incapacidade do Estado brasileiro em garantir as condições básicas para o desenvolvimento da cidadania. Neste quadro, muitas concepções de juventude compreendem o jovem ou como um fator de desestabilização da segurança na sociedade ou então como mera vítima de uma situação social, sem qualquer protagonismo, por também não compreender o seu

70 Cabe destacar que os levantamentos sobre homicídios realizados peridiocamente em nosso país, como por exemplo, as diversas edições do Mapa da Violência, publicados pelo Centro Brasileiro de Estudos Latino-Americanos e pela Faculdade Latino-Americanas de Ciências Sociais, trazem os dados sobre os homicídios mas não tratam da questão da autoria desses crimes. É fato que há uma escalada no número de jovens que são vítimas de homicídio mas não há sobre autoria desses crimes, ou seja, o Mapa não apresenta os dados sobre os homicídios cometidos por jovens. Até o presente momento, não foram localizados, dentre os documentos institucionais produzidos ou encomendados pelo Ministério da Justiça, dados que sustentem a afirmação de que os jovens são responsáveis pela maior parte dos homicídios no Brasil como sustenta a concepção do PRONASCI. 
papel na construção da segurança pública na sociedade. (MINISTÉRIO DA JUSTIÇA, 2008, p.4).

Buscando articular ações de prevenção e repressão da violência e criminalidade, o PRONASCI estabeleceu, para além do foco etário, um foco territorial para sua atuação, priorizando inicialmente as onze regiões metropolitanas do país com maiores índices de criminalidade e o Distrito Federal, numa classificação realizada pelo Ministério da Justiça, em parceria como o Ministério da Saúde ${ }^{71}$. Esta classificação utilizou-se do banco de dados do DATASUS para identificar as localidades com maiores índices de homicídio (CID10).

Sobre esta classificação, o Ministério da Justiça esclarece que:

Entre as regiões do País que apresentam alto índice de homicídios e delitos de origem social (outros crimes violentos), foram selecionadas cinco, conforme o documento Diagnóstico da Incidência de Homicídios nas Regiões Metropolitanas, produzido pela Secretaria Nacional de Segurança Pública, do Ministério da Justiça. Considerando o número de municípios, o Programa será desenvolvido em duas fases. Inicialmente será implementado nos seguintes Estados / municípios: Distrito Federal (Ride); Espírito Santo (Vitória, Serra, Vila Velha e Cariacica); Minas Gerais (Belo Horizonte, Betim, Contagem, Ribeirão das Neves, Santa Luzia e Ibirité); Pará (Belém e Ananindeua); Paraná (Curitiba, Colombo e São José dos Pinhais); Pernambuco (Recife, Olinda, Jaboatão dos Guararapes, Cabo de Santo Agostinho e Paulista); Rio de Janeiro (Rio de Janeiro, Nilópolis, Nova Iguaçu, São Gonçalo, Duque de Caxias, Queimados, Magé, Niterói, São João de Meriti e Belfort Roxo); São Paulo (São Paulo, Embu-Guaçu, Carapicuíba, Diadema, Itaquaquecetuba, Mauá, Osasco, Santo André, São Bernardo do Campo, Taboão da Serra, Suzano e Guarulhos); Rio Grande do Sul (Porto Alegre, São Leopoldo, Novo Hamburgo, Canoas e Alvorada); e Bahia (Salvador e Camaçari). (MINISTÉRIO DA JUSTIÇA, 2008b, p. 5).

71 No Estado do Paraná, em 2007 os municípios de Almirante Tamandaré, Araucária, Colombo, Curitiba, Piraquara e São José dos Pinhais assinaram Termo de Cooperação Federativa e aderiram ao PRONASCI. A partir de 2009, integraram o Programa os municípios de Cascavel, Catanduvas, Fazenda Rio Grande, Foz do Iguaçu, Maringá, Pinhais, Ponta Grossa e Toledo. O Consórcio Intermunicipal de Segurança Pública - CISMEL foi criado no Estado do Paraná com o objetivo de promover a adesão de municípios de Londrina e região ao PRONASCI. São integrantes do CISMEL e signatários do PRONASCI, os municípios de Londrina, Apucarana, Arapongas, Bela Vista do Paraíso, Cambé, Ibiporã, Jataizinho, Rolândia, Sertanópolis e Tamarana. 
Nestas áreas se concentrariam as ações de prevenção a violência estabelecendo assim um foco social para o Programa. A formação e valorização das forças de seguranças constituíam o foco policial do PRONASCI.

O Programa possuía 94 ações caracterizadas como ações estruturais, que visavam modernizar as polícias e o sistema prisional $^{72}$, valorizar os profissionais do setor, enfrentar a corrupção policial e o crime. Os programas locais, integrantes do PRONASCl, compreendiam as chamadas ações de prevenção destinadas "a retirar o jovem da rota criminal e inseri-lo nos programas governamentais já existentes, recuperando-os para a cidadania" (MINISTÉRIO DA JUSTIÇA, 2008a, p.5). As ações seriam executadas mediante convênio firmado entre o ente federado e a União. Nas regiões Sul e Sudeste, o ente federado respondia por uma contrapartida financeira de $2 \%$ do valor total do projeto. Nas regiões CentroOeste, Nordeste e Norte, o ente federado respondia por uma contrapartida financeira de $1 \%$ do valor total do projeto. ${ }^{73}$ As propostas elaboradas pelos entes federados, atendendo as orientações da SENASP, eram enviadas ao Ministério da Justiça e avaliadas pelo corpo técnico da SENASP. Caso fossem aprovadas, as propostas receberiam os recursos solicitados.

As chamadas ações de prevenção, com destaque para os projetos PROTEJO - Proteção de Jovens em Territórios Vulneráveis e Mulheres da Paz foram apresentadas pelo Ministério da Justiça como um novo paradigma para a Política Nacional de Segurança Pública.

Referindo-se à sobrevalorização da presença dos adolescentes como autores de crimes violentos, técnicos do IPEA - Instituto de Pesquisa Econômica Aplicada esclarecem que:

72 No Estado do Paraná, a Secretaria de Estado de Justiça e da Cidadania - SEJU firmou convênio com o Ministério da Justiça, no âmbito do PRONASCI, para construção de estabelecimento prisional, no município de Londrina, com 421 vagas destinadas a jovens entre 18 e 24 anos.

73 A percepção, pelo Governo Federal, da necessidade de adotar contrapartidas diferenciadas entre as regiões do Brasil é um indicativo das dificuldades presentes na execução de um programa federativa. No caso, trata-se da dificuldade de lidar com diferentes capacidades de investimento por parte dos entes federados envolvidos pelo programa. 
Os números mostram que isto não corresponde à realidade. O que ocorre, regularmente, é uma maior exposição e repercussão na mídia de episódios violentos envolvendo adolescentes o que leva a sociedade a acreditar que estão mais violentos ou são insuficientemente atingidos por ações penalizadoras. Quando se fala em jovens como principais vítimas e autores, muitas vezes se incluem os adolescentes, o que é válido somente para algumas análises. (AQUINO e ANDRADE, 2009, p. 193).

Em análise sobre as políticas públicas voltadas a juventude, técnicos do IPEA avaliam que "talvez o maior mérito do PRONASCI esteja precisamente em conciliar os conceitos de repressão e prevenção e aliar políticas de segurança pública com políticas sociais" (AQUINO e ANDRADE, 2009, p. 213). No entanto, é possível avaliar a conciliação proposta através da aplicação de recursos, no âmbito do Programa, em ações de prevenção e ações de repressão.

TABELA 1 Ações Orçamentárias - PRONASCI - 2008

\begin{tabular}{|l|l|}
\hline \multicolumn{1}{|c|}{ AÇÃO } & \multicolumn{1}{|c|}{ VALOR DE INVESTIMENTO } \\
\hline $\begin{array}{l}\text { Concessão de bolsa-formação a policiais militares e } \\
\text { civis, agentes penitenciárias, guarda-municipais, } \\
\text { bombeiros e peritos criminais, de baixa renda, } \\
\text { pertencentes aos Estados-membros. }\end{array}$ & $\mathrm{R} \$ 133.714 .486,45$ \\
\hline Campanha do Desarmamento. & $\mathrm{R} \$ 2.084 .911,54$ \\
\hline Apoio à implementação de políticas sociais. & $\mathrm{R} \$ 82.603 .516,32$ \\
\hline $\begin{array}{l}\text { Gestão e comunicação do PRONASCl*. } \\
\text { Fortalecimento de instituições de segurança pública. }\end{array}$ & $\mathrm{R} \$ 10.771 .504,50$ \\
\hline $\begin{array}{l}\text { Apoio à implementação de políticas de segurança } \\
\text { cidadã. }\end{array}$ & $\mathrm{R} \$ 118.874 .874,31$ \\
\hline $\begin{array}{l}\text { Valorização de profissionais e operadores de } \\
\text { segurança pública. }\end{array}$ & $\mathrm{R} \$ 38.893 .243,45$ \\
\hline
\end{tabular}

FONTE: FUNDAÇÂO GETỦLIO VARGAS, 2009.

* A ação Gestão e Comunicação do PRONASCI por se tratar de divulgação e implementação do Programa não foi classificada, para fins de análise, como ação de prevenção ou ação de repressão.

Considerando os valores apresentados na Tabela 1, observa-se que, no ano de $2008,47 \%$ do valor investido foi direcionado a ações de repressão, ou seja, de fortalecimento da repressão institucional a criminalidade e $53 \%$ foram 


\section{v. I. ก. 2. ago. 2013 - ARTIGOS}

direcionados a ações de prevenção ou, de acordo com a terminologia cunhada pelo Ministério da Justiça, de segurança cidadã,

Cabe destacar que $40 \%$ do valor total investido em ações de prevenção foi destinado à ação Bolsa Formação, iniciativa de educação à distância para capacitação de profissionais de segurança. Depreende-se desse apontamento uma primeira conclusão: o maior percentual investido pelo Programa não atingiu diretamente o foco etário ou social do Programa.

Quanto à distribuição de recursos entre os entes federados, o Gráfico 1 explicita que houve maior concentração de recursos, no ano de 2008, nas ações executadas pelos Estados. Essas ações, por conta da atribuição constitucional de gestão estadual das polícias militares e civis, estão em sua maioria relacionadas às atividades desses órgãos. É possível perceber que, em relação aos Estados, houve dificuldade de alinhamento com a proposta do Governo Federal. Houve, por parte destes entes federados, uma clara preferência por investimentos na repressão à violência em detrimento da perspectiva de prevenção a violência.

Os recursos executados por Municípios concentram, como tem sido o desenho institucional da política nacional de segurança pública, as ações de prevenção. As ações executadas pela União são aquelas chamadas de execução direta, ou seja, relacionadas a projetos executados pelo Ministério da Justiça, como por exemplo, a Campanha Nacional de Desarmamento. 
GRÁFICO 1 Destinação dos recursos para os entes federados - PRONASCI - 2008

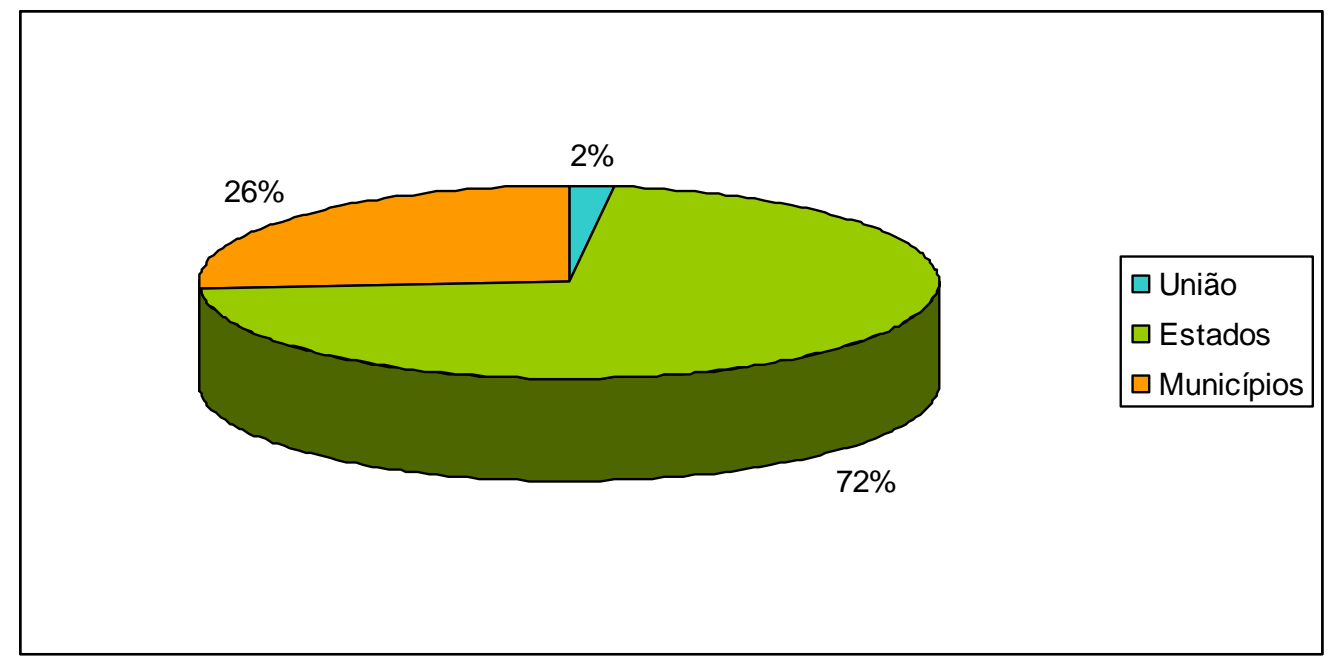

FONTE: FUNDAÇÂO GETÙLIO VARGAS, 2009.

O volume de recursos empenhados pelo Ministério da Justiça no âmbito da execução do PRONASCI pode ser considerado um marco histórico na descentralização de recursos. Não há precedentes na trajetória do Ministério da Justiça quanto aos repasses de recursos deste volume a Estados e Municípios. No entanto, constata-se facilmente que a demanda por recursos foi superior à oferta. Tomando como exemplo a região Sul, verifica-se que o número de projetos de convênios apresentados é superior ao número de convênios efetivamente firmados com os entes federados. Essa demanda frustrada ainda que possa estar, em parte, relacionadas a questões de ordem técnica (elaboração do projeto ou capacidade institucional para execução dos projetos) nos informa que a demanda por ações de segurança pública em esfera local foi subestimada pelo Governo Federal. 
TABELA 2 - Projetos apresentados por Estado - Região Sul - PRONASCI - 2008

\begin{tabular}{|l|l|l|l|}
\hline \multicolumn{1}{|c|}{ Estado } & Projetos enviados & Projetos aprovados & Valor de investimento \\
\hline Paraná & 27 & 3 & $\mathrm{R} \$ 1.923 .408,00$ \\
\hline Rio Grande do Sul & 94 & 36 & $\mathrm{R} \$ 36.408 .402,00$ \\
\hline Santa Catarina & 3 & 0 & - \\
\hline
\end{tabular}

FONTE: FUNDAÇÂO GETỦLIO VARGAS, 2009.

O repasse de recursos para região Sul bem como para as demais regiões brasileiras, assumiu, no ano de 2008, a seguinte configuração:

GRÁFICO 2 Percentual de valores pagos por região - PRONASCI - 2008

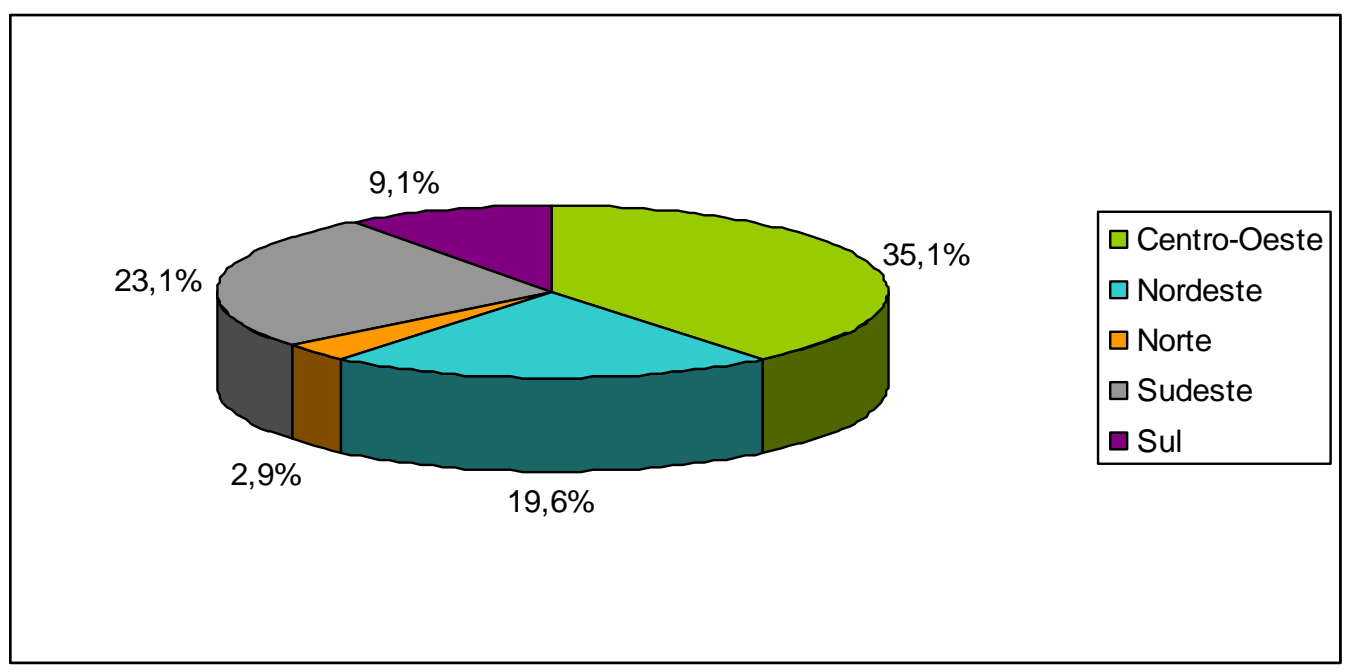

FONTE: FUNDAÇÂO GETÙLIO VARGAS, 2009.

Retoma-se, então, a questão dos pontos de partidas, apontada no início deste artigo. Entende-se que a existência de uma política de segurança pública institucionalizada constitui-se como fator determinante para acesso aos recursos descentralizados da política nacional de segurança pública. Ainda que tenha índices expressivos de violência, municípios e estados necessitam de expertise técnica para acessar os recursos e fomentar a política local. Os limites impostos pela realização deste trabalho não permitem a avaliação desta questão em profundidade. O gráfico 2, apresentado anteriormente, instiga a percepção da questão levantada. 
A continuidade no aporte de recursos também é um fator que dificultou o fomento de uma política local de segurança pública, a partir do PRONASCI. Tomando novamente o caso da região Sul houve queda nos valores investidos nos três estados que compõem a região. Faltam-nos os dados consolidados sobre o aporte de recursos nos anos seguintes (2010, 2011 e 2012), no entanto, a hipótese que se delineia é de que a diminuição de investimentos tenha permanecido.

TABELA 3 - Percentual de valores pagos - Região Sul - PRONASCI - 2007 - 2008

\begin{tabular}{|l|c|c|}
\hline \multicolumn{1}{|c|}{ Estado } & Valor de investimento 2008 & Valor de investimento 2009 \\
\hline Paraná & $\mathrm{R} \$ 16.636 .731,66$ & $\mathrm{R} \$ 8.506 .418,76$ \\
\hline Rio Grande do Sul & $\mathrm{R} \$ 46.047 .580,38$ & $\mathrm{R} \$ 39.862 .449,74$ \\
\hline Santa Catarina & $\mathrm{R} \$ 486.945,96$ & - \\
\hline
\end{tabular}

FONTE: FUNDAÇÂO GETU̇LIO VARGAS, 2009. FUNDAÇÃO GETÚLIO VARGAS, 2008.

A Fundação Getúlio Vargas contratada pelo Ministério da Justiça para monitorar e avaliar o início da execução do Programa apontou que:

O Ministério da Justiça, a partir da implementação do PRONASCI, ampliou o seu escopo de atividades e os níveis federativos envolvidos em suas políticas. Esse novo dimensionamento exigiu, por outro lado, a necessidade de maior capacidade de investimento e capilaridade de suas ações. Com a responsabilidade de induzir políticas públicas complexas, baseadas na articulação de distintos níveis federativos e sociais, uma demanda importante se apresenta: construir uma estrutura de gestão afinada segundo os objetivos estratégicos do programa. Tal qual se observou ao longo desse relatório, a estrutura administrativa de suporte do programa ainda não acompanhou por completo essa mudança, caracterizada pela complexidade das políticas desenvolvidas no âmbito do PRONASCl, encontrando-se em estágio de modernização com apoio da cúpula dirigente. Dessa forma, é necessário o aprimoramento da estrutura administrativa de forma a compatibilizá-las com o volume de recursos destinados às ações do programa. (FUNDAÇÃO GETÚLIO VARGAS, 2008, p. 101).

O PRONASCI apresentou dificuldades de execução em todo o país. Os principais obstáculos enfrentados por Estados e municípios para executarem os convênios celebrados com o Ministério da Justiça foram: a pulverização dos 
recursos no tempo e espaço ${ }^{74}$, a ausência de definição de critérios de seleção de propostas e do acompanhamento da execução das mesmas, o fluxo de relacionamento e comunicação com o Ministério da Justiça ${ }^{75}$ e a aplicação de modelos de projetos constituídos pela SENASP nas realidades locais. Para além destas questões de ordem técnica, prática e institucional, após a eleição de 2009, de acordo com dados da Fundação Getúlio Vargas, 54,88\% dos municípios PRONASCI sofreram mudança de gestão.

Quanto à questão da aplicação de modelos federais às realidades locais, SPOSITO e CARRANO (2003) observam que:

Projetos e programas são concebidos na esfera federal - por servidores públicos e agentes de organizações sociais não-governamentais consorciadas - e executados por municípios que, ansiosos por verbas federais não questionam diretrizes, métodos e metas pré-fabricadas.

No entanto, o choque com diretrizes, métodos e metas pré-fabricadas ocorre na execução, pelos entes federados, das ações pactuadas com o governo federal, momento em que o modelo de descentralização de recursos e da concepção de uma política nacional encontra sua aplicação prática em escala local, e portanto, com pequeno espaço para ajustes.

Em seu relatório de gestão, durante o primeiro ano de execução de ações do PRONASCI, a SENASP conclui que:

As ações tomadas atualmente como prioritárias na segurança pública ainda deixam intocado o principal problema a ser trabalhado: milhares de pessoas no Brasil, principalmente homens de 15 a 25 anos de idade, por total falta de condições dignas de vida, fizeram da ação criminosa sua profissão. Este problema nos obriga a promover uma ampliação do leque

74 A distribuição dos recursos do PRONASCI foi apresentada em relatório produzido pela Fundação Getúlio Vargas, no ano de 2009, intitulado PRONASCI em Números.

75 De acordo com a Fundação Getúlio Vargas: "Existe uma demanda por melhoria da comunicação do MJ com os demais entes federados, para um maior esclarecimento dos conceitos estruturantes do PRONASCI, bem como de suas ações. Isso também é válido para a sociedade civil, que, como ator importante nas ações do programa, necessita incorporar os seus conceitos nas práticas cotidianas de suas políticas. Uma maior divulgação, baseada no entendimento dos pressupostos do programa, é central para ampliar a participação em torno de suas ações, como também de sua legitimação junto à sociedade. Esses canais de divulgação mais fortes, estruturados com os entes federados e à sociedade, permitirão o fortalecimento dos GGls e a apresentação de novos projetos mais focados com a lógica do PRONASCI. (FUNDAÇÃO GETÚLIO VARGAS, 2008, p. 101). 
de instituições a fazerem parte do SUSP, pois as polícias não podem ser vistas como as únicas organizações responsáveis pelos problemas de segurança pública. É preciso promover uma ampliação dos responsáveis por esta área incluindo outras organizações governamentais (lazer, trabalho, saúde, educação, infra-estrutura urbana, etc.) e também não governamentais e a própria sociedade. Neste contexto, a SENASP tem uma importância fundamental para a melhoria da situação da segurança pública no Brasil, promovendo o reforço do papel dos policiais, bombeiros e guardas como protagonistas de uma cultura democrática, inclusiva e de promoção de direitos (MINISTÉRIO DA JUSTIÇA, 2008a, p. 59).

As dificuldades encontradas na execução dos convênios firmados foram responsáveis por um grande percentual de devolução de recursos para a União ${ }^{76}$. Em resposta a esta situação, a SENASP instituiu uma equipe de fiscalização de convênios, responsável por assessorar Estados e Municípios na elaboração de projetos para convênio e na execução das ações previstas. Em 2010, foram propostas, pela SENASP, mudanças na gestão do Programa buscando atingir as metas estabelecidas pelo PRONASCl em sua concepção.

O PRONASCI aparenta ter perdido sua força a partir de 2011, ano marcado pela extinção da Secretaria Executiva do PRONASCI, unidade gestora criada, dentro da Secretaria Executiva do Ministério da Justiça. Suas ações passaram a ser incorporadas, como ações isoladas, nos editais do FNSP e houve diminuição em torno da publicidade ou divulgação do Programa. Tal fato é atestado por Cano (2006, p.146), que o observa o fato de que "os planos nacionais estão sujeitos a vai-e-vem, atrasos ou paradas e podem entrar em colapso ou perder a força rapidamente quando mudam as condições políticas. De fato, a maioria dos programas demonstra uma preocupante falta de continuidade".

No ano de 2011, o Ministério da Justiça assumiu a coordenação com o Ministério da Saúde do Programa Crack, é possível vencer ${ }^{77}$. O Programa, integrante do Plano Integrado de Enfretamento ao Crack e outras Drogas, que também conta com a participação dos ministérios do Desenvolvimento Social e

76 Para exemplificar esta questão: em recente reportagem, o Jornal Gazeta do Povo aponta que foram devolvidos à União pelo Estado do Paraná $R \$ 800.000,00$, recursos recebidos por meio do PRONASCI e não executados pela Secretaria Estadual de Segurança Pública. (MARCHIORI, 2012).

77 As informações sobre o Programa Crack, é possível vencer estão disponíveis no endereço $<$ www.brasil.gov.br/enfrentandoocrack/home $>$. 
Combate à Fome e da Educação, reúne um conjunto de ações destinadas aos usuários e dependentes do uso de drogas. As ações estão organizadas em três eixos: Prevenção, Cuidado e Autoridade. $O$ eixo de Prevenção faz referência às estratégias voltadas a prevenção ao uso de drogas por meio de ações de educação, de informação e capacitação. As estratégias de ampliação da oferta e qualificação de serviços de saúde para tratamento e atenção aos usuários e seus familiares integram o eixo de Cuidado. Sob responsabilidade do Ministério da Justiça, mais especificamente da SENASP, o eixo Autoridade tem previstas as ações de enfrentamento ao tráfico e ao crime organizado e policiamento ostensivo em locais de concentração de uso de crack, associado ao acompanhamento destes por meio de videomonitoramento.

Para além das ações voltadas para a repressão do uso de drogas em locais públicos e ao narcotráfico, em 27 de junho de 2012, o ministro da Justiça José Eduardo Cardozo lançou o Programa Brasil mais seguro ${ }^{78}$ como uma tentativa de redução do número de homicídios no Brasil. O Programa é composto por três eixos de atuação: a melhoria da investigação de mortes violentas, por meio de investimentos em tecnologia, o fortalecimento do policiamento ostensivo e comunitário e o controle das armas e assim como o Programa Crack, é possível vencer, é executado mediante a assinatura de termos de cooperação com Estados e Municípios.

Os dois novos programas coordenados pelo Ministério evidenciam a ruptura com a proposta de segurança pública com cidadania do PRONASCI. Há, em seus conteúdos, um deslocamento das ações de prevenção, apresentadas como elemento inovador no PRONASCl, para as ações de repressão a criminalidade, em especial, a criminalidade violenta e não há referência a juventude como uma questão particular. Portanto, é possível apontar que o programa de prevenção à violência não impulsionou o surgimento de uma política

78 Dada a ausência de informações institucionais sobre o Programa Brasil Mais Seguro, no Portal do Ministério da Justiça, as informações relativas ao lançamento do Programa foram retiradas de matéria intitulada Em novo plano nacional, governo aposta em tecnologia e mais policiamento para reduzir criminalidade, disponível no Portal UOL. 
nacional de combate da mortalidade e criminalidade da juventude como se pretendia.

Faz-se necessário analisar a execução do PRONASCI, a partir da disponibilização dos dados referentes aos anos de 2010, 2011 e 2012, para que seja avaliada a extensão dos resultados alcançados pelo Programa em sua breve trajetória. Este é o próximo objetivo a ser perseguido.

\section{REFERÊNCIAS}

AQUINO, Luseni Maria C de e ANDRADE, Carla Coelho de (orgs.). Juventude e políticas sociais no Brasil. Brasília: IPEA, 2009.

ARRETCHE, Marta Teresa da Silva. Estado federativo e políticas sociais: determinantes da descentralização. São Paulo: FAPESP, 2000.

BANCO MUNDIAL. Jovens em situação de risco no Brasil. Volume I Achados relevantes para as Políticas Públicas (Policy Briefing). Brasília: Banco Mundial, 2007.

BRASIL. Lei n. 8.069, de 13 de julho de 1999. Altera dispositivos do Decreto no 1.796, de 24 de janeiro de 1996, que aprova a Estrutura Regimental do Ministério da Justiça. Diário Oficial [da] República Federativa do Brasil. Brasília, DF, 5 set de 1997. Disponível em: < http://www.planalto.gov.br/ccivil 03/leis/L8069.htm>. Acesso em 17 mar 2013.

BRASIL. Lei n. 10.201, de 14 de fevereiro de 2001. Institui o Fundo Nacional de Segurança Pública - FNSP, e dá outras providências. Diário Oficial [da] República Federativa do Brasil. Brasília, DF, 16 fev de 2001. Disponível em: <http://www.planalto.gov.br/ccivil_03/leis/LEIS_2001/L10201.htm >. Acesso em 23 ago 2012.

BRASIL. Lei n. 11.530, de 24 de outubro de 2007. Institui o Programa Nacional de Segurança Pública com Cidadania - PRONASCI e dá outras providências. Diário Oficial [da] República Federativa do Brasil. Brasília, DF, 25 out de 2007. Disponível em: < http://www.planalto.gov.br/ccivil_03/_ato20072010/2007/Lei/L11530.htm>. Acesso em 23 ago 2012.

BRASIL. Constituição da República Federativa do Brasil: promulgada em 5 de outubro de 1988. São Paulo: Saraiva, 2007. Coleção Saraiva de legislação. 
BRASIL. Portal do Programa Crack, é possível vencer. Disponível em: <www.brasil.gov.br/enfrentandoocrack/home>. Acesso em 23 agosto 2012.

CANO, Ignácio. Políticas de Segurança Pública no Brasil: Tentativas de modernização e democratização versus a guerra contra o crime. SUR - Revista Internacional de Direitos Humanos. [online] Número 5. Ano 3. 2006. P. 136-155.

FUNDAÇÃO GETÚLIO VARGAS. PRONASCI em perspectiva. Brasília: FGV, 2008.

. PRONASCI em números. Brasília: FGV, 2009.

MADEIRO, Carlos. Em novo plano nacional, governo aposta em tecnologia, e mais policiamento para reduzir criminalidade. UOL Notícias. Maceió, 27 junho 2012. Disponível em: <http://noticias.uol.com.br/cotidiano/ultimasnoticias/2012/06/27/em-novo-plano-nacional-governo-aposta-em-tecnologia-emais-policiamento-para-reduzir-criminalidade.htm>. Acesso em 23 agosto 2012.

MARCHIORI, Raphael. Em 5 anos, PR aplicou só um terço do investimento previsto em segurança. Gazeta do Povo. Curitiba, 14 agosto 2012. Vida e Cidadania. Disponível em:

<http://www.gazetadopovo.com.br/vidaecidadania/conteudo.phtml?id=1286255\&ch $=>$. Acesso em 23 agosto 2012 .

MINISTÉRIO DA JUSTIÇA. Plano Nacional de Segurança Pública. Brasília: 2000.

MINISTÉRIO DA JUSTIÇA. SENASP. Guia para a prevenção do crime e da violência. Brasília: 2005. Disponível em: <www.mj.gov.br>. Acesso em: 14 set. 2011.

MINISTÉRIO DA JUSTIÇA. Um novo paradigma para segurança pública. Brasília: 2008.

MINISTÉRIO DA JUSTIÇA. SENASP. Relatório de Gestão. Brasília: 2008a. Disponível em: <www.mj.gov.br>. Acesso em 14 set. 2011.

SANTOS, Wanderley Guilherme dos. A práxis liberal e a cidadania regulada. In: . Décadas de espantos e uma apologia democrática. Rio de Janeiro:

Rocco, 1998. p. $1-30$.

SECRETARIA DE DIREITOS HUMANOS et al. Guia Municipal de Prevenção da Violência Letal contra Adolescentes e Jovens. Rio de Janeiro: Observatório de Favelas, 2012. 
SPOSITO, Marília Pontes e CARRANO, Paulo César Rodrigues. Juventudes e políticas públicas no Brasil. Revista Brasileira de Educação. №. 24. Rio de Janeiro: set/out, 2003. 